\title{
ANALYSIS OF STUDENTS' AND TRAM DRIVERS' BODY RATIOS IN Order to Simplify THE CONTROL PANel DESign
}

\author{
Sandro Tokić, Davor Sumpor, Srećko Đuranović \& Nedžad Musabašić
}
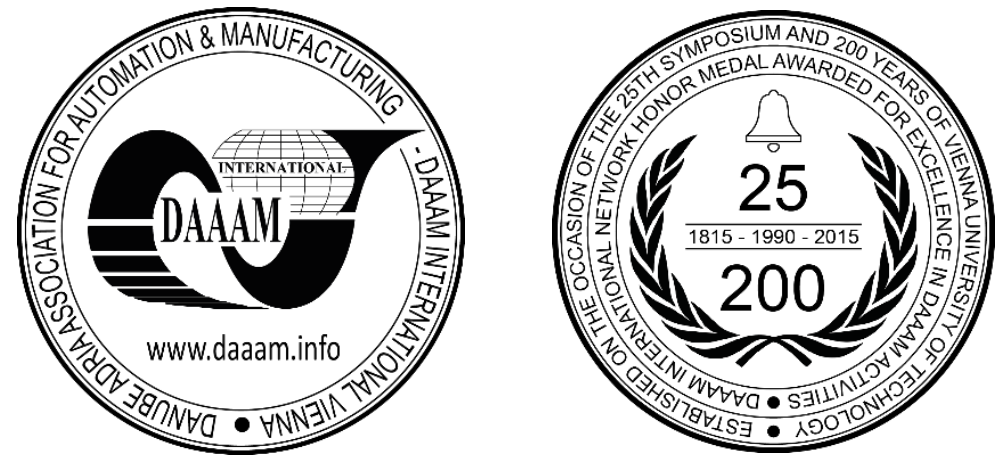

This Publication has to be referred as: Tokic, S[andro]; Sumpor, D[avor]; Duranovic, S[recko] \& Musabasic, N[edzad] (2017). Analysis of Students' and Tram Drivers' Body Ratios in Order to Simplify the Control Panel Design, Proceedings of the 28th DAAAM International Symposium, pp.0875-0884, B. Katalinic (Ed.), Published by DAAAM International, ISBN 978-3-902734-11-2, ISSN 1726-9679, Vienna, Austria

DOI: $10.2507 / 28$ th.daaam.proceedings. 122

\begin{abstract}
A total of 10 anthropometric measures were taken from a sample of 21 male tram drivers of ZET Zagreb, from a sample of 39 male students of the University of Zagreb, as well as from a sample of 48 female students of the University of Zagreb, out of which the mean arithmetic values of body segment ratios were determined. According to the scientific findings that body height decreases with age, male tram drivers were divided by age into three groups. Some of the calculated mean arithmetic values of body segment ratios $h_{i} / h$ for individual anthropometric measures $h_{i}$ in relation to the body height $h$ have been compared with theoretical values of body ratios calculated by harmonic analysis by Zerderbauer and Muftic and the golden section, and it is obvious that there are no big differences in values. Body ratios $h_{m d r} / h$ and $h_{n d r} / h$ can be used for simplified calculation of anthropometric measures $h_{m d r}$ and $h_{n d r}$ only by knowing the value of body height $h$, during the control panel design in tram cab or train cab, because body ratios $h_{m d r} / h$ and $h_{n d r} / h$ do not depend on gender, age and occupation for adult respondents from Croatia.
\end{abstract}

Keywords: anthropometric measures; theoretic harmonic analysis; golden section; body segment ratios; simplified calculation

\section{Introduction}

The main objective of all the human body harmonic analyses, such as harmonic analysis by Zederbauer and Muftić [1], is to ensure a more accurate and more simplified way to calculate other anthropometric measures, based only on knowing one measured anthropometric measure, which is the most common standing body height $h$. Generally considered, the widely known are the following significant five groups of factors of the human body sizes [2, 3, 4, 5, 6]: gender, age, ethnic differences, socioeconomic factors and demographic factors. In accordance with the proved scientific claims that the gender, age and socioeconomic factors of participants significantly affect body height, the researchers have wondered: "Is it possible that the gender, age and socioeconomic factors of respondents do not significantly affect body ratios $h_{i} / h$ in relation to the current standing body height $h$ for anthropological measures $h_{i}$ important for cabin design?" In the smaller part of the study whose results are published in this paper the participants were male and female students of the University of Zagreb and male tram drivers of ZET Zagreb. 
The presented results represent only a smaller part of the larger scale research which includes several separate studies of male engine drivers from all regions of Croatia [7], male and female tram drivers of ZET Zagreb and male and female students of the University of Zagreb.

\section{Harmonic circle by Zederbauer and Muftić}

The construction of the harmonic circle with radius $R$ was given by Zederbauer at the beginning of the last century, in the way that the harmonic circle is a geometrical structure of an isosceles triangle, on whose sides there are lifted squares. The relations between radius of the circle $R$ and the length of the sides of isosceles triangle $a$ and $b$ are always one and the same harmonic numbers, regardless of the change in size of the circle radius. Muftic chose the diameter of the harmonic circle $2 R$ for the human body height $h$, so the network of canon of eight head heights $h_{g}$ is associated with the diameter of the harmonic circle and the human body height, so in this way are established the connection between harmonic numbers and anthropometric measures of the human, according to equation (1) and Figure 1 [1].

$$
2 \cdot R=h=8 \cdot h_{g}
$$

The circle in Figure 1 is known in literature under the name of harmonic circle by Zerderbauer and Muftić [1], from whose constructions the sizes called harmonic numbers are obtained, according to Table 1.

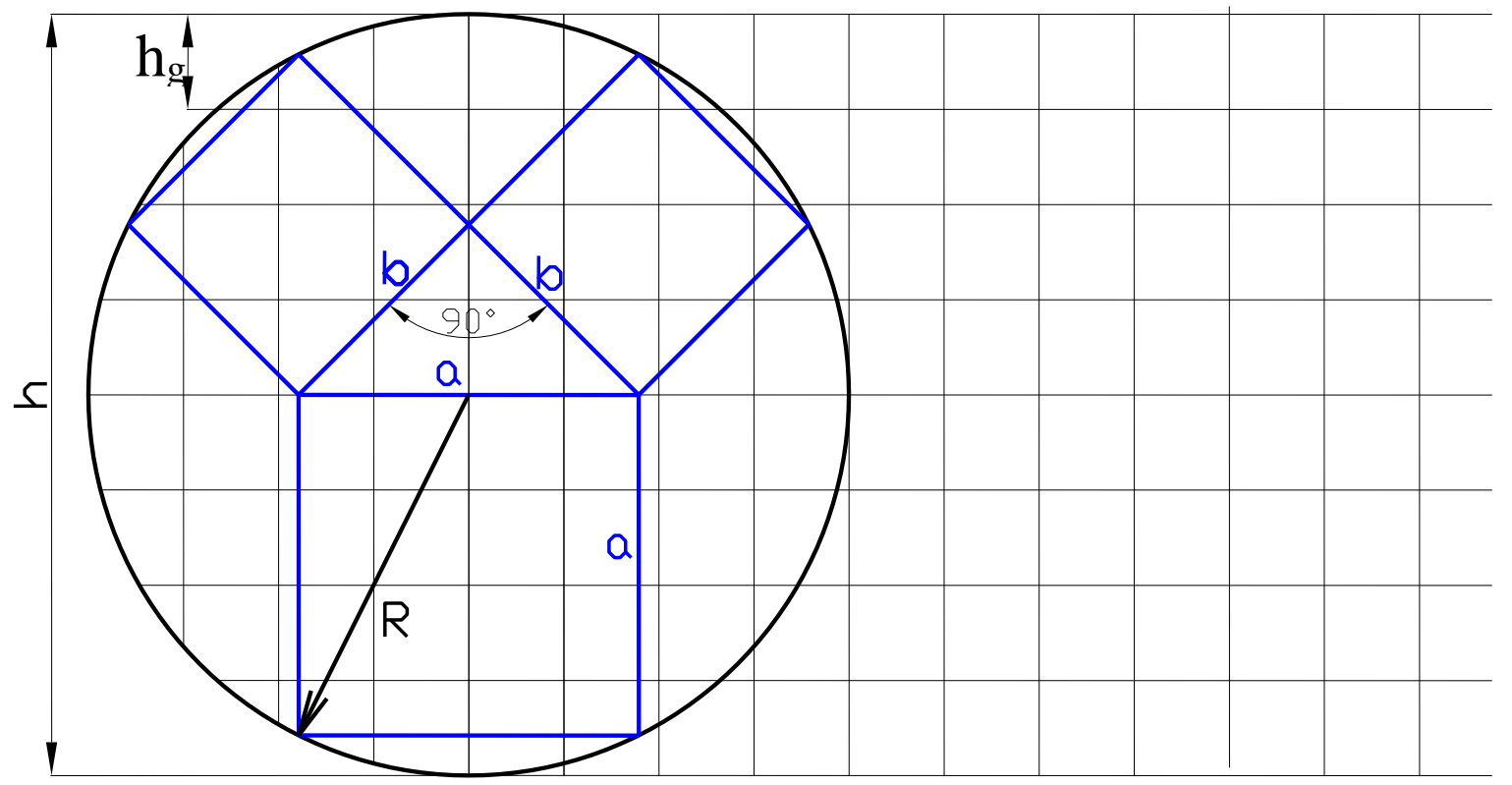

Fig. 1. Harmonic circle by Zederbauer and Muftic with associated canon of eight head heights as a measure for the standing body height

Source: Modified taken from Muftić, O. et al., Zagreb, 2001 [1])

\begin{tabular}{|c|c|c|c|c|c|}
\hline \multicolumn{3}{|c|}{ Basic harmonic sizes: } & \multicolumn{3}{|c|}{ Derived harmonic sizes: } \\
\hline Label: & $\begin{array}{c}\text { Connection } \\
\text { with } a:\end{array}$ & $\begin{array}{c}\text { Amount } \\
\text { for } a=1:\end{array}$ & Label: & Connection with basic harmonic sizes: & $\begin{array}{c}\text { Amount } \\
\text { for } a=1:\end{array}$ \\
\hline$a$ & $1 \mathrm{a}$ & 1 & $r_{h}$ & $=b-\frac{a}{2}=\frac{\sqrt{2}-1}{2} \cdot a$ & 0,207 \\
\hline$b$ & $\frac{\sqrt{2}}{2} \cdot a$ & 0,707 & $d_{h}$ & $=R-\frac{a}{2}=\frac{\sqrt{5}-1}{2} \cdot a$ & 0,618 \\
\hline$R$ & $\frac{\sqrt{5}}{2} \cdot a$ & 1,118 & $b+r_{h}$ & $=\frac{\sqrt{2}}{2} \cdot a+\left(b-\frac{a}{2}\right)=\frac{2 \sqrt{2}-1}{2} \cdot a$ & 0,914 \\
\hline
\end{tabular}

Table 1. Harmonic sizes as harmonic numbers

Source: Modified taken from Muftić, O. et al., Zagreb, 2001 [1] 


\begin{tabular}{|c|c|c|c|c|c|}
\hline $\begin{array}{c}\text { Length of } \\
\text { body segment: }\end{array}$ & $\begin{array}{c}\text { Label of } \\
\text { length }\end{array}$ & $\begin{array}{c}\text { Function } \\
h i=h i(h):\end{array}$ & $\begin{array}{c}\text { Length of } \\
\text { body segment }\end{array}$ & $\begin{array}{c}\text { Label of } \\
\text { length }\end{array}$ & $\begin{array}{c}\text { Function } \\
h i=h i(h):\end{array}$ \\
\hline $\begin{array}{c}\text { Length } \\
\text { of arm }\end{array}$ & $h_{r}$ & $=\frac{25}{64} h=0.39 \cdot h$ & $\begin{array}{c}\text { length } \\
\text { of upper arm }\end{array}$ & $h_{n d l}$ & $=\frac{5}{32} h=0.156 \cdot h$ \\
\hline $\begin{array}{c}\text { Length } \\
\text { of forearm }\end{array}$ & $h_{p d l}$ & $=\frac{h}{8}=0.125 \cdot h$ & $\begin{array}{c}\text { length } \\
\text { of hand }\end{array}$ & $h_{\check{s}}$ & $=\frac{7}{64} h=0.109 \cdot h$ \\
\hline $\begin{array}{c}\text { Leg } \\
\text { length }\end{array}$ & $h_{n}$ & $=\frac{17}{32} h$ & $\begin{array}{c}\text { length of } \\
\text { upper leg }\end{array}$ & $h_{3}$ & $=\frac{9}{32} h$ \\
\hline $\begin{array}{c}\text { Length of } \\
\text { lower leg }\end{array}$ & $h_{2}$ & $=\frac{7}{32} h$ & $\begin{array}{c}\text { foot } \\
\text { length }\end{array}$ & $h_{1}$ & $\frac{h}{8}$ \\
\hline $\begin{array}{c}\text { Length of the mobile } \\
\text { part of the spine in the } \\
\text { standing position }\end{array}$ & $h_{k}$ & $=\frac{1}{3} h$ & $h_{11}$ & $\frac{h}{32}$ \\
\hline
\end{tabular}

Table 2. Anthropometric measures of a human as a function of a standing body height $h$ Source: Modified, taken from Muftić, O. et al., Zagreb, 2001 [1]

Harmonic analysis of the human shows that functions of the anthropometric sizes i.e. segmental lengths depend on the standing body height of the human, on the basis of the relationship according to equation (1). All functions $h i=h i(h)$ which are shown in Table 2 should be universally valid for the young and healthy subjects of both genders.

According to many authors $[3,5,6]$, age and gender are significant factors of body stature. The whole development of body dimensions reaches its peak towards the end of teenage or $20 \mathrm{~s}$ in men, while women reach this development a few years earlier. After maturity, the body dimensions of both genders begin to decrease with age which is illustrated in Figure 2.

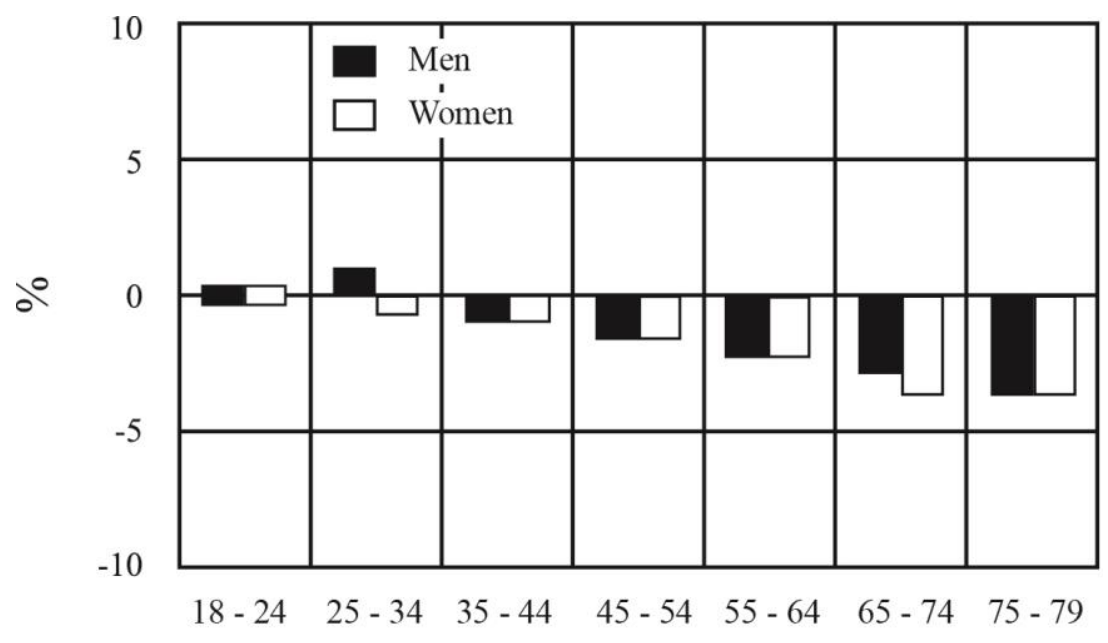

Years

Fig. 2. Relative changes in body stature depending on age and gender, for men and women at the age of 18 to 79 Source: Taken from the National Center for Health Statistics, 1965 [6]

However, in reality, there are minor deviations of functional dependencies i.e. body segment ratios $h_{i} / h$ of anthropometric sizes $h_{i}$ about the standing body height $h$ between men and women, which have been analysed in this paper on male and female students. Also, possible deviations of the real body segment ratios have been analysed in relation to theoretical values shown in Table 2 which were calculated using the harmonic analysis by Zederbaur and Muftić.

Relative changes of body segment ratios $h_{i} / h$ with age have been analysed on the male tram drivers from Zagreb, who were divided into three age groups.

The anthropomeasures variations in adult men and women compared to the dimensional canon of eight head heights are within the range of one module, i.e. it is considered that the total standing body height of a human can vary within an interval of 7.5 to 8.5 head heights; however, it can be even 9 head heights for the so-called heroically built people [2]. This scientific claim for the value of the body ratio $h / h_{g}$ between standing body height $h$ and head height $h_{g}$ has been verified and confirmed in this paper on the male and female students of the University of Zagreb until the age of 29, as well as on the male tram drivers in Zagreb, divided into three age groups. 


\section{Analysis of the human body based on the golden section}

The geometric construction of the golden ratio [3] is illustrated on the rectangular triangle shown in Figure 3. The standing body height $h$ is divided in two parts, the larger section i.e. height to the navel $h_{B}$, and the smaller section i.e. height above the navel $h_{C}$, which is shown in Figure 4.

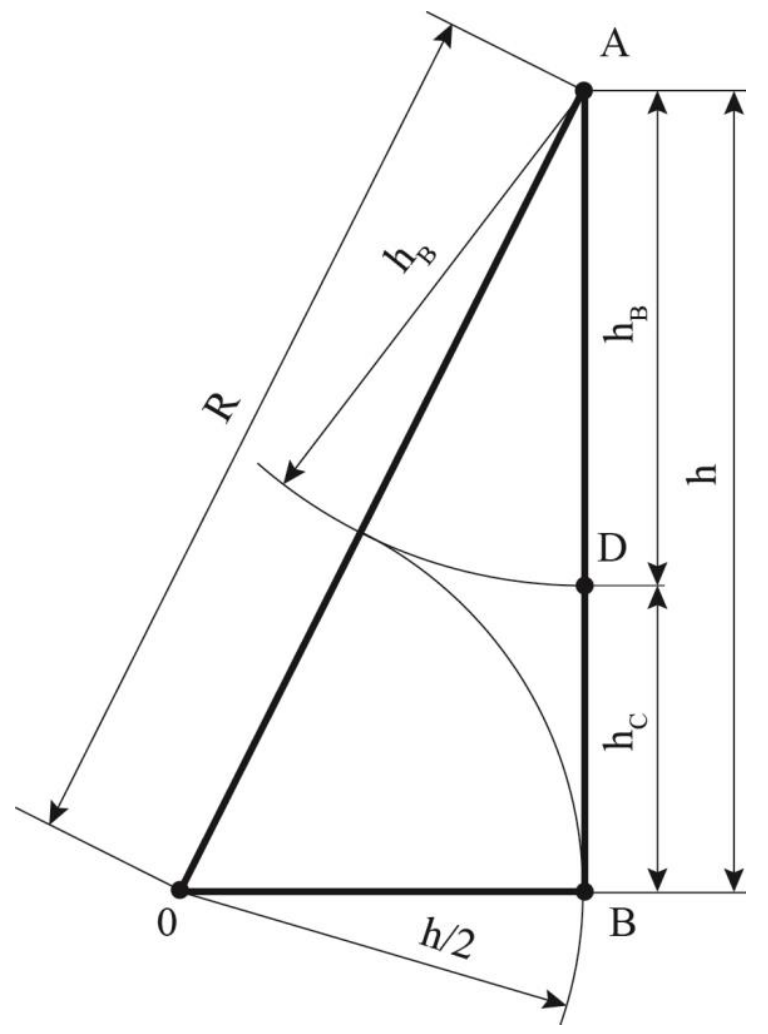

Fig. 3. Analysis of the human body based on the golden section Source: Modified, taken from Ujević, D. et al., Zagreb, 2009 [3]

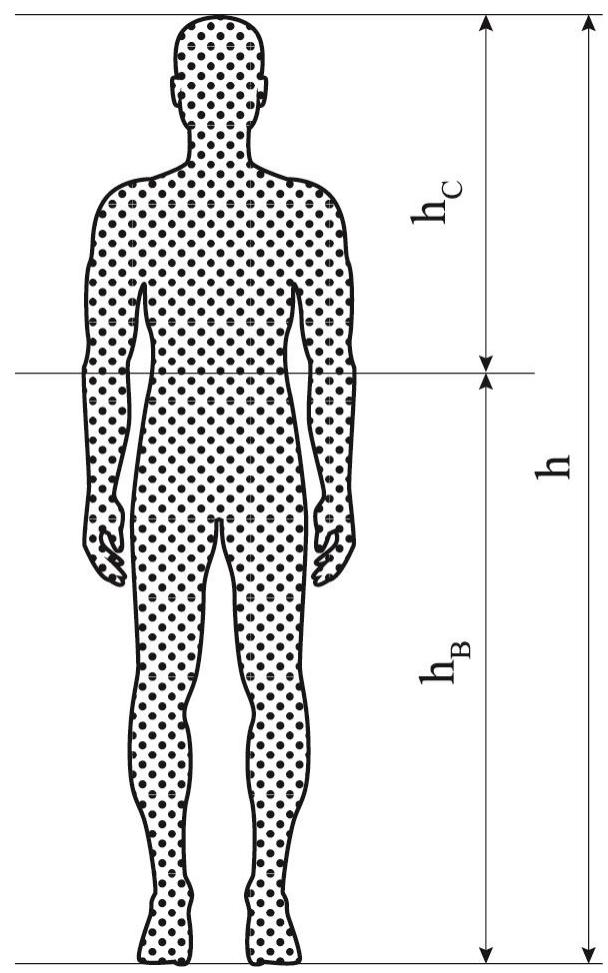

Fig. 4. Human body and the golden section 
From the rectangular triangle $\triangle \mathrm{OAB}$ shown in Figure 3 there follows:

$$
\begin{aligned}
& R=h / 2+h_{B} \\
& R^{2}=h^{2}+(h / 2)^{2}=5 / 4 h^{2} \\
& R=\sqrt{\frac{5 h^{2}}{4}}=\frac{\sqrt{5}}{2} h=1,1180 \cdot h \\
& h_{B}=R-h / 2=\frac{\sqrt{5}}{2} h-h / 2=0.618 \cdot h \\
& h_{B} / h=0.618 \\
& h_{C}=h-h_{B}=h-0.6180 \cdot h=0.3819 \cdot h \\
& h_{C} / h=0.3819 \\
& h_{C} / h_{B}=h_{B} / h=0.618
\end{aligned}
$$

It is obvious that the theoretical value of the golden section is 0.618 in accordance with equation (6) and model shown in Figures 3 and 4. The paper presents a deviation of the real values of the body ratio $h_{B} / h$ in all groups of respondents in relation to the theoretical value of the golden section 0.618 .

\section{Results}

For all groups of respondents (male and female students of the University of Zagreb and male tram drivers in Zagreb) only a few of the most important anthropometric measures were measured, shown in Table 4 for male tram drivers in Zagreb (for the entire sample, and for sample divided into three age groups). Dynamic anthropometric measures maximum arm reach $h_{m d r}$ and normal arm reach $h_{n d r}$ together with static anthropometric measure bi-acromial range (shoulder width) $h_{\check{s} r}$ are the most important anthropometric measures for control panel design in the tram cabin.

The static anthropometric measures of the length of upper arm $h_{n d l}$ and the length of forearm $h_{p d l}$ were calculated using the measured values of the next three static anthropometric measures: arm length $h_{r}$, length of forearm and hand $h_{10}$ and hand length $h_{s}$. The distance from the floor to the navel $h_{B}$ was measured for the purpose of calculating the real value of ratio $h / h_{B}$ for the golden section, for all groups of respondents.

If the arithmetic mean $M$ and sample standard deviation $S D$ are known, then 5 centile and 95 centile for all anthropometric measures can be calculated, according to equations (7) and (8) taken from Kroemer and Grandjean [4], because $5 \%$ of the tallest and $5 \%$ of the shortest individuals of the entire sample of respondents should be excluded (in the physical dimension to which the analysis applies).

$$
\begin{aligned}
& 5,0 \cdot c=M-1,65 \cdot S D \\
& 95,0 \cdot c=M+1,65 \cdot S D
\end{aligned}
$$

If we have a mixed population of drivers (as a mixed male-female population of tram drivers of ZET operator in Zagreb), the range of anthropometric measures for central $90 \%$ should be calculated as a range between 5 centile for females (for the age group with the smallest values of anthropometric measures) and 95 centile for males (for the age group with the biggest values of anthropometric measures). But this is not the main objective of this research. The static and dynamic anthropometric measures were used for the calculation of body segment ratios $h_{i} / h$ for anthropometric measure $h_{i}$ in relation to the standing body height $h$.

Figure 5 shows typical anthropometric measures in the sagittal plane with labels by Kroemer and Muftić [1, 4]. Label 19 was added by co-authors. 


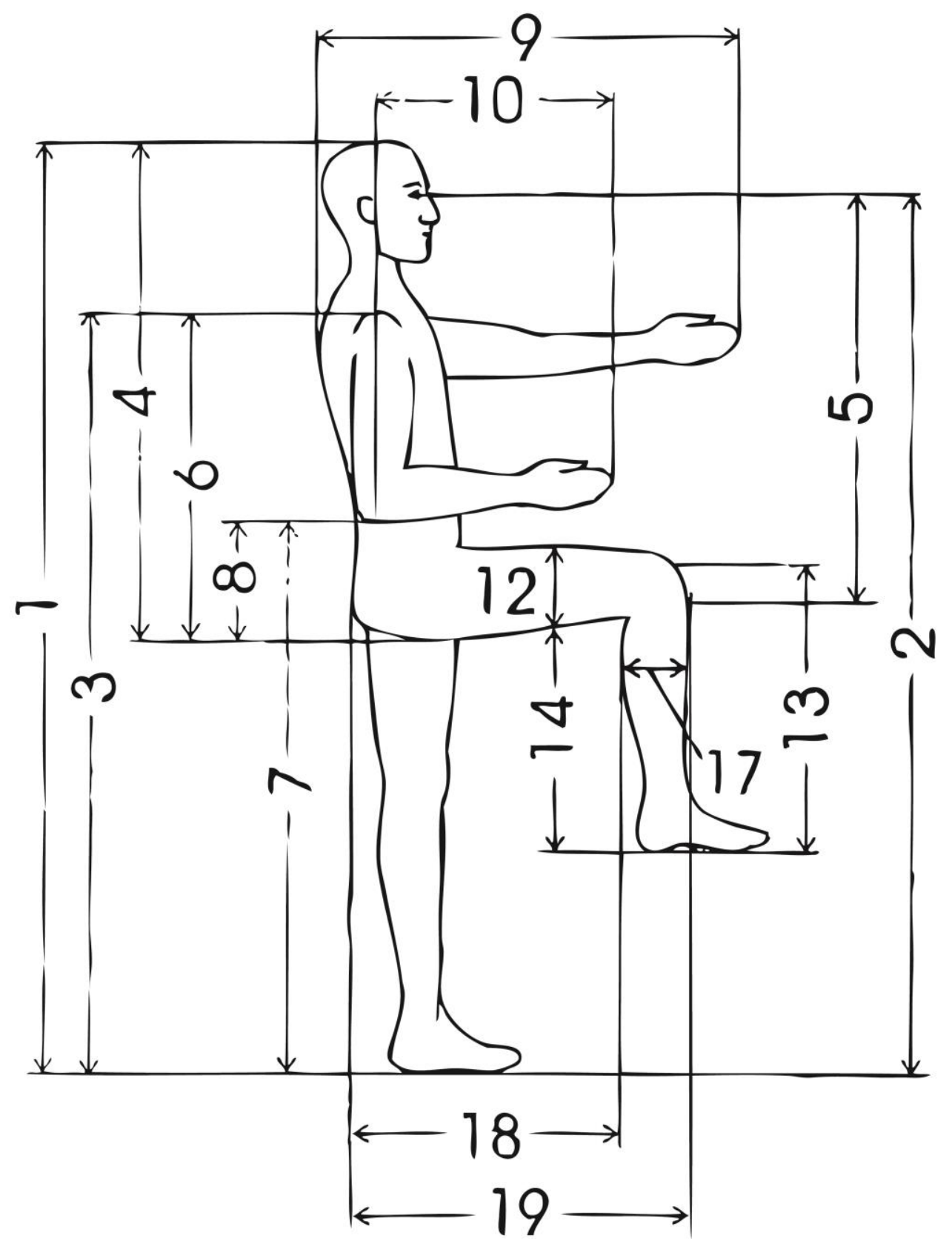

Fig. 5. Showing typical anthropometric measures in the sagittal plane by Kroemer Source: Complemented, taken from Muftić, O., Milčić, D. 2001 [1]

The results of a few own studies confirm that gender is a significant factor of body stature. The age of fifty-one (51) researched engine drivers from Croatia, which are in the range from 27 to 56 years of age, significantly affects body height $h$ and other anthropometric measures $h_{i}$ that are functionally dependent on the body height $h$ [7], which is for body height $h$ confirmed by the results shown in Table 3 .

\begin{tabular}{|c|c|c|c|c|c|c|c|c|c|c|c|}
\hline \multirow{3}{*}{$\begin{array}{l}\text { Anthropomet } \\
\text { ric measure }\end{array}$} & \multirow{3}{*}{ 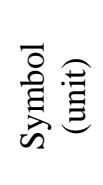 } & \multicolumn{10}{|c|}{ Age groups } \\
\hline & & \multicolumn{2}{|c|}{$\begin{array}{c}\text { Total sample } \\
(n=51)\end{array}$} & \multicolumn{2}{|c|}{$\begin{array}{c}\text { Up to } 29 \text { years } \\
(n=9)\end{array}$} & \multicolumn{2}{|c|}{$\begin{array}{l}\text { From } 30 \text { up } 39 \\
\text { years }(n=13)\end{array}$} & \multicolumn{2}{|c|}{$\begin{array}{l}\text { From } 40 \text { up } 49 \\
\text { years }(n=18)\end{array}$} & \multicolumn{2}{|c|}{$\begin{array}{l}\text { From } 50 \text { up } 59 \\
\text { years }(n=11) \\
\end{array}$} \\
\hline & & $M$ & $S D$ & $M$ & $S D$ & $M$ & $S D$ & $M$ & $S D$ & $M$ & $S D$ \\
\hline Body height & $h(\mathrm{~cm})$ & 178.9 & 5.7 & 177.2 & 6.0 & 180.6 & 6.2 & 178.6 & 6.1 & 178.5 & 4.0 \\
\hline
\end{tabular}

Table 3. Body height of male engine drivers in Croatia depending on age groups Source: Taken from Mikulčić, M. et al., 2015 [7] 
The values of anthropometric measures for male tram drivers in Zagreb shown in Table 4 partially confirm that age is a significant factor of body stature, because the largest value of arithmetic mean $M$ of body height $h$ is in the age group from 30 up to 39 years of age.

But the arithmetic mean of body height $h$ in the age group from 50 up to 59 years is not the smallest value, and possible reasons for this deviation of results shown in Table 4 can be: insufficient total number of tram drivers in the sample, unequal and insufficient number of tram drivers in three age groups, as well as possible impacts of demographic factors within a particular age group (the origin of tram drivers from different parts of Croatia was not analysed and not taken into account during the sampling).

\begin{tabular}{|c|c|c|c|c|c|c|c|c|c|c|}
\hline \multirow{4}{*}{$\begin{array}{c}\text { Name of the anthropometric measures } \\
\text { or body segments }\end{array}$} & \multirow{4}{*}{ 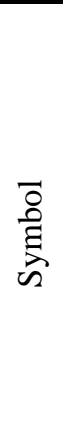 } & \multirow{4}{*}{ 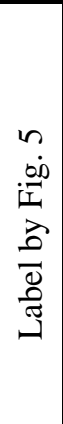 } & \multirow{2}{*}{\multicolumn{2}{|c|}{$\begin{array}{c}\begin{array}{c}\text { Total } \\
\text { sample }\end{array} \\
n=21\end{array}$}} & \multirow{2}{*}{\multicolumn{2}{|c|}{$\begin{array}{c}\text { From } 30 \text { up to } \\
39 \text { years } \\
n=5\end{array}$}} & \multirow{2}{*}{\multicolumn{2}{|c|}{$\begin{array}{c}\text { From } 40 \text { up } \\
\text { to } 49 \text { years }\end{array}$}} & \multirow{2}{*}{\multicolumn{2}{|c|}{$\begin{array}{l}\text { From } 50 \text { up } \\
\text { to } 59 \text { years } \\
n=8\end{array}$}} \\
\hline & & & & & & & & & & \\
\hline & & & $M$ & $S D$ & $M$ & $S D$ & $M$ & $S D$ & $M$ & $S D$ \\
\hline & & & $\begin{array}{c}\mathrm{cm} \\
\left(\mathrm{kg}^{*}\right)\end{array}$ & $\begin{array}{c}\mathrm{cm} \\
\left(\mathrm{kg}^{*}\right)\end{array}$ & $\begin{array}{c}\mathrm{cm} \\
\left(\mathrm{kg}^{*}\right)\end{array}$ & $\underset{\left(\mathrm{kg}^{*}\right)}{\mathrm{cm}}$ & $\begin{array}{c}\mathrm{cm} \\
\left(\mathrm{kg}^{*}\right)\end{array}$ & $\begin{array}{c}\mathrm{cm} \\
\left(\mathrm{kg}^{*}\right)\end{array}$ & $\begin{array}{c}\mathrm{cm} \\
\left(\mathrm{kg}^{*}\right)\end{array}$ & $\begin{array}{c}\mathrm{cm} \\
\left(\mathrm{kg}^{*}\right)\end{array}$ \\
\hline Standing body height & $h$ & 1 & 179.6 & 6.00 & 182.0 & 5.10 & 177.8 & 6.52 & 180.0 & 6.02 \\
\hline Mass* & $m$ & & 95.1 & 17.4 & 94.1 & 16.07 & 91.8 & 16.53 & 98.9 & $\begin{array}{c}20.2 \\
7\end{array}$ \\
\hline $\begin{array}{l}\text { Arm length (from acromion to the tip of } \\
\text { the middle finger in vertical position) }\end{array}$ & $h_{r}$ & & 78.2 & 3.49 & 79.0 & 4.36 & 76.6 & 3.16 & 79.3 & 3.06 \\
\hline $\begin{array}{l}\text { Length of forearm and hand (from rare } \\
\text { side of the elbow to the tip of the } \\
\text { middle finger in a horizontal position) }\end{array}$ & $h_{10}$ & 10 & 48.6 & 2.11 & 49.2 & 2.17 & 48.0 & 2.51 & 48.9 & 1.73 \\
\hline Length of upper arm & $h_{n d l}$ & & 29.6 & 1.99 & 29.8 & 2.49 & 28.6 & 0.92 & 30.4 & 2.26 \\
\hline Length of forearm & $h_{p d l}$ & & 28.6 & 1.43 & 29.0 & 1.73 & 28.4 & 1.69 & 28.5 & 1.07 \\
\hline $\begin{array}{r}\text { Hand length (distance between tip of } \\
\text { the middle finger and the first crease in } \\
\text { the wrist) }\end{array}$ & $h_{\check{s}}$ & & 20.0 & 1.02 & 20.2 & 0.84 & 19.6 & 1.06 & 20.4 & 1.06 \\
\hline Distance from the navel to the floor & $h_{B}$ & & 105.0 & 3.99 & 108.6 & 2.30 & 104.3 & 3.11 & 103.6 & 4.57 \\
\hline $\begin{array}{l}\text { Normal arm reach (from the rear side of } \\
\text { the elbow to the middle of a clenched } \\
\text { fist) }\end{array}$ & $h_{n d r}$ & & 35.6 & 1.91 & 36.4 & 1.67 & 34.9 & 1.96 & 35.8 & 1.98 \\
\hline $\begin{array}{r}\text { Maximum arm reach (from the rear side } \\
\text { of the acromion to the middle of a } \\
\text { clenched fist) }\end{array}$ & $h_{m d r}$ & & 64.6 & 2.94 & 65.4 & 3.85 & 63.9 & 3.56 & 64.8 & 1.58 \\
\hline Bi-acromial range (shoulder width) & $h_{\check{s} r}$ & 15 & 39.5 & 2.68 & 38.0 & 3.54 & 40.3 & 2.43 & 39.8 & 2.25 \\
\hline
\end{tabular}

Table 4. Static and dynamic anthropometric measures of male tram drivers in Zagreb depending on age 


\begin{tabular}{|c|c|c|c|c|c|c|c|c|c|c|c|c|}
\hline \multirow{3}{*}{$\begin{array}{l}\text { Body segment } \\
\text { ratios or } \\
\text { golden section } \\
\text { ratios }\end{array}$} & \multicolumn{4}{|c|}{$\begin{array}{c}\text { Male students up to } 29 \\
\text { years of age }\end{array}$} & \multicolumn{4}{|c|}{$\begin{array}{c}\text { Female students up to } 29 \\
\text { years of age }\end{array}$} & \multicolumn{4}{|c|}{$\begin{array}{c}\text { Male tram drivers in } \\
\text { Zagreb from } 30 \text { up to } 59 \\
\text { years of age }\end{array}$} \\
\hline & \multicolumn{4}{|c|}{$n=39$} & \multicolumn{4}{|c|}{$n=48$} & \multicolumn{4}{|c|}{$n=21$} \\
\hline & $M_{r}$ & $S D_{r}$ & min. & $\max$. & $M_{r}$ & $S D_{r}$ & $\min$. & $\max$. & $M_{r}$ & $S D_{r}$ & min. & $\max$ \\
\hline$h_{B} / h$ & 0.61 & 0.015 & 0.58 & 0.66 & 0.60 & 0.013 & 0.57 & 0.62 & 0.59 & 0.015 & 0.55 & 0.61 \\
\hline$h_{C} / h_{B}$ & 0.63 & 0.040 & 0.52 & 0.72 & 0.66 & 0.036 & 0.61 & 0.76 & 0.71 & 0.045 & 0.64 & 0.83 \\
\hline$h_{C} / h$ & 0.39 & 0.015 & 0.34 & 0.42 & 0.40 & 0.013 & 0.38 & 0.43 & 0.42 & 0.016 & 0.39 & 0.45 \\
\hline$h / h_{g}$ & 8.10 & 0.660 & 6.73 & 9.37 & 8.38 & 0.481 & 7.43 & 9.26 & 8.06 & 0.340 & 7.50 & 8.75 \\
\hline$h_{r} / h$ & 0.44 & 0.017 & 0.40 & 0.47 & 0.43 & 0.013 & 0.41 & 0.47 & 0.43 & 0.012 & 0.41 & 0.46 \\
\hline$h_{n d l} / h$ & 0.17 & 0.015 & 0.13 & 0.20 & 0.17 & 0.012 & 0.14 & 0.20 & 0.16 & 0.009 & 0.15 & 0.18 \\
\hline$h_{p d l} / h$ & 0.15 & 0.008 & 0.14 & 0.17 & 0.15 & 0.008 & 0.13 & 0.16 & 0.16 & 0.006 & 0.15 & 0.17 \\
\hline$h_{\check{S}} / h$ & 0.12 & 0.006 & 0.10 & 0.13 & 0.11 & 0.005 & 0.11 & 0.12 & 0.11 & 0.005 & 0.10 & 0.12 \\
\hline$h_{m d r} / h$ & 0.36 & 0.020 & 0.33 & 0.40 & 0.36 & 0.016 & 0.32 & 0.40 & 0.36 & 0.015 & 0.33 & 0.39 \\
\hline$h_{n d r} / h$ & 0.20 & 0.014 & 0.16 & 0.24 & 0.20 & 0.010 & 0.16 & 0.22 & 0.20 & 0.008 & 0.18 & 0.21 \\
\hline$h_{s r} / h$ & 0.20 & 0.019 & 0.16 & 0.23 & 0.20 & 0.018 & 0.17 & 0.24 & 0.22 & 0.015 & 0.20 & 0.24 \\
\hline
\end{tabular}

Table 5. Body segment ratios and the golden section ratios of male and female students of the University of Zagreb and male tram drivers in Zagreb

Results in Tables 5 and 6 show that all mean values $M_{r}$ of the golden section ratios $h_{B} / h$ for all groups of respondents (for both genders and for all age groups of tram drivers) deviate very little from the theoretical value of the golden section which is 0.618 . The largest range of variations of the golden section ratios $h_{B} / h$ around the mean arithmetic value $M_{r}$ is for the male students of up to 29 years of age, from the minimal 0.58 up to the maximal 0.66 .

\begin{tabular}{|c|c|c|c|c|c|c|c|c|c|c|c|c|}
\hline \multirow{3}{*}{$\begin{array}{l}\text { Body segment } \\
\text { ratios or } \\
\text { golden section } \\
\text { ratios }\end{array}$} & \multicolumn{4}{|c|}{$\begin{array}{c}\text { Male tram drivers from } 30 \\
\text { up to } 39 \text { vears }\end{array}$} & \multicolumn{4}{|c|}{$\begin{array}{c}\text { Male tram drivers from } 40 \\
\text { up to } 49 \text { vears }\end{array}$} & \multicolumn{4}{|c|}{$\begin{array}{c}\text { Male tram drivers from } 50 \\
\text { up to } 59 \text { vears }\end{array}$} \\
\hline & \multicolumn{4}{|c|}{$n=5$} & \multicolumn{4}{|c|}{$n=8$} & \multicolumn{4}{|c|}{$n=8$} \\
\hline & $M_{r}$ & $S D_{r}$ & min. & $\max$. & $M_{r}$ & $S D_{r}$ & $\min$. & $\max$. & $M_{r}$ & $S D r$ & min. & $\max$. \\
\hline$h_{B} / h$ & 0.60 & 0.009 & 0.59 & 0.61 & 0.59 & 0.009 & 0.57 & 0.60 & 0.58 & 0.019 & 0.55 & 0.60 \\
\hline$h_{C} / h_{B}$ & 0.68 & 0.026 & 0.64 & 0.71 & 0.70 & 0.025 & 0.66 & 0.74 & 0.74 & 0.058 & 0.66 & 0.83 \\
\hline$h_{C} / h$ & 0.40 & 0.009 & 0.39 & 0.41 & 0.41 & 0.009 & 0.40 & 0.43 & 0.42 & 4.50 & 0.40 & 0.45 \\
\hline$h / h_{g}$ & 8.13 & 0.354 & 7.78 & 8.71 & 8.06 & 0.423 & 7.50 & 8.75 & 8.01 & 0.271 & 7.57 & 8.38 \\
\hline$h_{r} / h$ & 0.43 & 0.015 & 0.42 & 0.46 & 0.43 & 0.012 & 0.41 & 0.45 & 0.44 & 0.008 & 0.43 & 0.45 \\
\hline$h_{n d l} / h$ & 0.16 & 0.010 & 0.15 & 0.18 & 0.16 & 0.004 & 0.15 & 0.17 & 0.17 & 0.011 & 0.15 & 0.18 \\
\hline$h_{p d l} / h$ & 0.16 & 0.007 & 0.15 & 0.17 & 0.16 & 0.008 & 0.15 & 0.17 & 0.16 & 0.005 & 0.15 & 0.17 \\
\hline$h_{s} / h$ & 0.11 & 0.005 & 0.10 & 0.12 & 0.11 & 0.004 & 0.10 & 0.12 & 0.11 & 0.003 & 0.11 & 0.12 \\
\hline$h_{m d r} / h$ & 0.36 & 0.016 & 0.34 & 0.38 & 0.36 & 0.018 & 0.33 & 0.39 & 0.36 & 0.014 & 0.34 & 0.39 \\
\hline$h_{n d r} / h$ & 0.20 & 0.010 & 0.19 & 0.21 & 0.20 & 0.009 & 0.18 & 0.21 & 0.20 & 0.007 & 0.19 & 0.21 \\
\hline$h_{\check{s r}} / h$ & 0.21 & 0.016 & 0.19 & 0.23 & 0.23 & 0.010 & 0.22 & 0.24 & 0.22 & 0.015 & 0.20 & 0.24 \\
\hline
\end{tabular}

Table 6. Body segment ratios and golden section ratios of male tram drivers in Zagreb depending on age

Results in Tables 5 and 6 show that all mean values $M_{r}$ of the body ratios $h / h_{g}$ for all groups of respondents (for both genders and for all age groups of tram drivers) deviate very little from the theoretical value based on the canon of eight head heights $h_{g}$ which is 8 . There is a small difference between the mean arithmetic value of the body ratio for male students $\left(h / h_{g}=8.1\right)$ and the mean arithmetic value of the body ratio for female students $\left(h / h_{g}=8.38\right)$. 
The largest range of variations of body ratios $h / h_{g}$ is around the mean arithmetic value $M_{r}$ for male students up to 29 years, from minimal 6.73 up to the maximum of 9.37 (variations gain value of 2.64 head heights). Differences of the mean arithmetic values of body ratios $h / h_{g}$ for tram drivers in relation to the theoretical value $h / h_{g}=8$ decrease depending on age; for male tram drivers from 50 up to 59 years of age, the body ratio $h / h_{g}$ is 8.01 .

Results shown in Tables 5 and 6 confirm that there is no big difference between the mean arithmetic values of body ratios $h_{r} / h$ (ratio of arm length and body height), $h_{n d l} / h$ (ratio of length of upper arm and body height), $h_{p d l} / h$ (ratio of length of forearm and body height) and $h_{\mathfrak{s}} / h$ (ratio of hand length and body height) depending on gender (male and female students), age (three age groups of male tram drivers) and occupation (students and tram drivers).

Mean arithmetic values of body ratios $h_{r} / h$ and $h_{5} / h$ of all groups of respondents shown in Tables 5 and 6 are almost same with the mean arithmetic values of body ratios $h_{r} / h$ and $h_{\mathfrak{S}} / h$ of all four age groups for fifty one (51) researched engine drivers from Croatia, which were in the range from 27 to 56 years of age in 2015 [7]; and also those are almost the same with the mean arithmetic values of body ratios $h_{r} / h$ and $h_{s} / h$ of 68 female student from the University of Zagreb in 2016 (another sample from the same population) [8].

Mean arithmetic values of body ratios $h_{\mathcal{S}} / h$ and $h_{n d l} / h$ of all groups of respondents are almost the same with the theoretical values shown in Table 2 which are based on the harmonic analysis and body height $h$ defined by the canon of eight head heights $h_{g}$.

Mean arithmetic values of body ratios $h_{r} / h$ and $h_{p d l} / h$ of all groups of respondents are different in relation to the theoretical values of body ratios shown in Table 2 which are based on the harmonic analysis, because real mean arithmetic values of body ratio $h_{r} / h$ are bigger in relation to the theoretical value $h_{r} / h=0.39$ for ca. $13 \%$, and the real mean arithmetic values of body ratio $h_{p d l} / h$ are bigger in relation to the theoretical value $h_{p d l} / h=0.125$ for ca. $28 \%$.

Mean arithmetic values of body ratios $h_{m d r} / h=0.36$ (ratio of maximum arm reach and body height) and $h_{n d r} / h=0.2$ (ratio of normal arm reach and body height) of all groups of respondents shown in Tables 5 and 6 are completely the same with the mean arithmetic values of body ratios $h_{m d r} / h$ and $h_{n d r} / h$ of all four age groups for fifty one (51) researched engine drivers from Croatia [7], and also those are completely the same with the mean arithmetic values of body ratios $h_{m d r} / h$ and $h_{n d r} / h$ of 68 female students from the University of Zagreb in 2016 (another sample from the same population) [8]. Generally considering, dynamic anthropometric measures, maximum arm reach $h_{m d r}$ and normal arm reach $h_{n d r}$ are linear functionalities depending on the standing body height $h$ [7], and this fact can be the reason why those body ratios do not depend on the changes of body height depending on age.

Body ratios $h_{m d r} / h$ and $h_{n d r} / h$ can be used for simplified calculation of values of anthropometric measures $h_{m d r}$ and $h_{n d r}$ only by knowing the value of the body height $h$, during the control panel design in tram cab or train cab, because real mean arithmetic values of body ratios $h_{m d r} / h=0.36$ and $h_{n d r} / h=0.20$ do not depend on gender, age and occupation for adult respondents from Croatia. Quick and simplified calculation of normal arm reach $h_{n d r}$ is very important, because frequently used commands on the locomotive, railcar or tram control panel need to be arranged mainly within the normal reach of the arm, using multi-purpose controllers for serving several important and frequently used functions by one hand, whenever possible [9].

Mean arithmetic values of body ratios $h_{s} / h$ of all groups of respondents shown in Tables 5 and 6 are not the same. The range of variations of mean arithmetic values of body ratio $h_{s \grave{r}} / h$ is from minimal 0.20 (male and female students up to 29 years) up to the maximum 0.23 (male tram drivers from 40 up to 49 years). Static anthropometric measure biacromial range (shoulder width) $h_{\check{s} r}$ have to be measured for all respondents divided into age groups from target population of drivers, and the mean arithmetic value of body ratio $h_{s r} / h$ cannot be used for simplified calculation of the value of anthropometric measure $h_{\check{s} r}$ only by knowing the value of body height $h$. The available studies [10] also indicate very weak correlations $(r=0.42)$ between bi-acromial range (shoulder width) and body height $h$ in males $(r=0.42)$, which means that there are no linear functional dependences $h \check{s} r=h \check{s} r(h)$.

\section{Discussion and conclusion}

The largest part of the measured participants are not harmonic beings. Just a few respondents have body dimensions in accordance to the golden section and harmonic analysis by Zederbauer and Muftic based on the canon of eight head heights $h_{g}$.

But the calculated mean arithmetic values of body segment ratios $h_{i} / h$ for individual anthropometric measures $h_{i}$ in relation to the body height $h$ have not deviated significantly from the theoretical values of the body ratios calculated by the harmonic analysis by Zerderbauer and Muftić and the golden section. Between the analysed body ratios the biggest deviation is for body ratio $h_{p d} / h$ (ratio of the length of forearm and body height), and real mean arithmetic values of body ratio $h_{p d l} / h$ are ca. $28 \%$ bigger in relation to the theoretical value calculated by Zerderbauer and Muftić.

Much more important results of this study are that the real mean arithmetic values of body ratios $h_{m d r} / h=0.36$ (ratio of maximum arm reach and body height) and $h_{n d r} / h=0.2$ (ratio of normal arm reach and body height) can be used for simplified and quick calculation of the values of anthropometric measures $h_{m d r}$ and $h_{n d r}$ only by knowing the value of the body height $h$, during the control panel design in tram cab or train cab, because of real mean arithmetic values of body ratios $h_{m d r} / h$ and $h_{n d r} / h$ do not depend on gender, age, and occupation (socioeconomic factors) for adult respondents from Croatia.

This partial study is not finished, and will be continued with improvements during the sampling as follows. 
There was an insufficient total number of tram drivers in the sample; the number of tram drivers in three age groups was unequal and insufficient; there were no tram driver respondents of up to 29 years of age; there were no tram driver respondents over 60, and possible impacts of demographic factors within a particular age group (the origin of tram drivers from different parts of Croatia was not analysed and was not taken into account during the sampling). Since the population of tram drivers of the ZET operator in Zagreb is mixed male-female, anthropometric measures should also be measured for female tram drivers, for all age groups, for the purpose of comparing the results of the mean arithmetic values of body ratios $h_{i} / h$ with the results presented in this paper.

Of course, for a final study conclusion and final results of the larger scale research the results published in this paper will be compared with the results of other planned participants. If it is necessary due to mathematical and methodological reasons, some of the partial research will be repeated with a bigger number of respondents.

The final results of the larger scale research should not be limited only to tram and train drivers in Croatia.

\section{Acknowledgments}

Authors are grateful to female and male students of the University of Zagreb and tram drivers of ZET Zagreb, who were participants of this study. Without their cooperation, this study could not have been carried out. Also, special thanks to the representative of the Association of Croatian Trade Unions of Drivers and Transport Workers Mr. Anto Jelić for his patience in coordinating the research in ZET Zagreb. This study is supported by the Faculty of Transport and Traffic Sciences, University of Zagreb, under the name "Program of support for establishing of the research activities and groups PROM-PRO 995-12 (2017)“.

\section{References}

[1] Muftić, O., Milčić, D. (2001). Ergonomija u sigurnosti, Visoka škola za sigurnost na radu, Iproz, Zagreb

[2] Jurum-Kipke, J., Baksa, S., Kavran, Z. (2007). Anthropometric Relations of Human Body in the Function of Traffic Environment Analysis, Proceedings of 3rd International Ergonomics Conference "Ergonomics 2007“, June 13-16, 1007, Stubičke toplice, ISBN: 978-953-98741-4-6, Mijović, B. et al. (ed.), pp. 239-247, Croatian Ergonomics Society, Zagreb

[3] Ujević, D. et al. (2009). Theoretical Aspects and Application of Croatian Anthropometric System, Faculty of Textile Technology, University of Zagreb, ISBN: 978-953-7105-28-0, Zagreb

[4] Kroemer, K.H.E.; Grandjean, E. (1997). Fitting the Task to the Human, A Textbook of Occupational Ergonomics, Fifth Edition, Published by Taylor \& Francis Ltd., ISBN: 0748406654, London, (K.H.E. Kroemer, E. Grandjean, Prilagođavanje rada čovjeku, Naklada Slap, Jastrebarsko, 2000., ISBN: 953-191-096-0).

[5] Panero, J.; Zelnik, M. (1979). Human dimension \& Interior space, Watson Guptill Publications, ISBN: 0-82307271-1, New York

[6] https://www.cdc.gov/nchs/data/series/sr_11/sr11_008.pdf, (1965). U.S. Department of Health, Education and Weffare, National Center for Health Statistic, Weight, Height, and Selected Body Dimensions of Adults, Series 11, Number 8, Rockwille, Maryland, USA, Accessed on: 2016-10-23

[7] Mikulčić, M.; Modrić, M.; Sumpor, D. (2015). Application Possibility of Engine Drivers' Body Segments Ratios in Designing the Cab' Working Environment in Croatia, Proceedings of the 26th DAAAM International Symposium on Intelligent Manufacturing and Automation, DAAAM 2015, Zadar, 21st - 24th October 2015, ISSN: 1726-9679, Katalinić, B. (ed.), pp. 842-848, Published by DAAAM International, Vienna

[8] Sumpor, D.; Mikulčić, M.; Modrić, M. (2016). Female Students' Body Segments Ratios, Book of Proceedings of the 6th International Ergonomics Conference „Ergonomics 2016 - Focus on synergy“, June15-18, 2016, Zadar, ISSN: 1848-9699, Sušić, A. et al. (ed.), pp. 323-330, Croatian Ergonomics Society, Zagreb

[9] Sumpor, D.; Taboršak, D.; Jurum-Kipke, J. (2015). Anthropometric Measures Important for Control Panel Design in Locomotive or Railcar, Technical Gazette, Scientific proffesional journal of technical faculties of the Josip Juraj Strossmayer University of Osijek, Vol.22, No.1, Slavonski Brod, 2015, pp. 1-10, ISSN: 1330-3651

[10] Ozaslan, A.; Karadayi, B.; Kolusayin, M.O.; Kaya, A. (2011). Stature Estimation from Bi-acromial and Bi-iliocristal Measurements, Romanian Journal of Legal Medicine, Romanian Society of Legal Medicine, Vol.19, No.3, Bucharest, 2011, pp. 171-176, ISSN: 1844-8585 